\title{
Estratégias comunicacionais de redução e direcionamento da visibilidade nas mídias sociais: práticas discursivas e sociotécnicas
}

Communication strategies for reducing and targeting social media visibility: discursive and sociotechnical practices

Estrategias de comunicación a la reducción y orientación de la visibilidad en las redes sociales: prácticas discursivas y sociotécnicas

Diego Wander da Silva

- Professor na Escola de Comunicação, Artes e Design da Pontifícia Universidade Católica do Rio Grande do Sul (Famecos-PUCRS).

- Professor substituto na Faculdade de Biblioteconomia e Comunicação da Universidade Federal do Rio Grande do Sul (Fabico-UFRGS).

- Doutor pelo Programa de Pós-Graduação em Comunicação e Informação da UFRGS.

- Mestre em Comunicação Social pelo Programa de Pós-Graduação em Comunicação Social da PUCRS.

- E-mail: dwander.silva@gmail.com 


\section{Resumo}

O objetivo deste artigo é refletir sobre as estratégias de redução e direcionamento da visibilidade nas mídias sociais, evidenciando condutas que atendam a esses desejos divulgadas em estudos científicos publicados entre 2019 e 2021. Tais alternativas se caracterizam pelo alto grau de profissionalização e por responderem apenas aos interesses organizacionais. Recorremos à Teoria Fundamentada em Dados para selecionar pesquisas aderentes. Como resultados, destacamos o avanço de bots sociais e a incipiência de investigações dedicadas a desvelar níveis de envolvimento das organizações.

PALAVRAS-CHAVE: COMUNICAÇÃO ORGANIZACIONAL • ESTRATÉGIAS • MÍDIAS SOCIAIS • REDUÇÃO DA VISIBILIDADE • DIRECIONAMENTO DA VISIBILIDADE.

\section{Abstract}

This article aims to discuss the strategies for reducing and targeting social media visibility, presenting practices reported in scientific studies published between 2019 and 2021. Such alternatives are characterized by a high degree of professionalization and by responding only to organizational interests. Studies were selected based on the data-driven theory. The results highlight the progress of bots and the incipience of investigations addressing organizations involvement levels.

\section{KEYWORDS: ORGANIZATIONAL COMMUNICATION・STRATEGIES・SOCIAL MEDIA・VISIBILITY REDUCTION・VISIBILITY TARGETING.}

\section{Resumen}

Este artículo pretende reflexionar sobre las estrategias de reducción y orientación de la visibilidad en las redes sociales, destacando las conductas que cumplieron esta intención divulgadas en estudios científicos entre 2019 y 2021. Estas alternativas se caracterizan por un alto grado de profesionalización y por responder únicamente a intereses organizacionales. Para seleccionar los estudios adherentes, se utilizó la teoría fundamentada. Como resultado, destacamos el progreso de bots sociales y las incipientes investigaciones dedicadas a revelar los niveles de participación de las organizaciones. 


\section{INTRODUÇÃO}

$\mathrm{N}$ osso estudo se insere nas discussões sobre comunicação organizacional nas ambiências digitais. Especificamente, aborda práticas das organizações nas mídias sociais, empregadas com o intuito de evitar associações com pautas sensíveis, potencialmente geradoras de crises de imagem e abalos reputacionais. Em termos de conformação, tais estratégias ora são predominantemente discursivas, ora se valem do manejo de recursos sociotécnicos. Pesquisa realizada por Silva e Baldissera (2019) mapeou um conjunto de estratégias com essa intencionalidade, por meio de investigação empírica com profissionais que atuam em agências de comunicação digital brasileiras. Esse estudo redimensionou nossa atenção, visto que algumas dessas alternativas representam potencial de dano aos públicos, porque influenciam nos processos de formação de opinião. Nos bastidores, há interesses e disputas por determinados sentidos - pouco conhecidos e tensionados em um debate social mais amplo. Ou seja, há um desconhecimento profundo, inclusive na academia.

São objetivos deste artigo: refletir sobre as estratégias comunicacionais de redução e direcionamento da visibilidade nas mídias sociais e evidenciar condutas que atendam a esses desejos, divulgadas em estudos científicos publicados em periódicos entre 2019 e 2021. A opção por essa demarcação temporal tem o propósito de agregar pontos de vista posteriores ao mapeamento dessas práticas por Silva e Baldissera (2019)'. Nossa lente epistêmica é o interacionismo simbólico (Littlejohn, 1982), o que nos permite assumir que a comunicação se efetiva mediante trocas simbólicas e que os significados são produtos sociais que emergem das interações. Alinhados a essa perspectiva, compreendemos que as estratégias comunicacionais se constituem a partir de práticas sociais, como sugerem Bulgacov e Marchiori (2010), e não como propriedade das organizações.

Em relação aos procedimentos metodológicos, a pesquisa, de caráter exploratório (Gil, 2021), propõe inicialmente uma discussão teórica. Para responder ao segundo objetivo, recorremos à Teoria Fundamentada nos Dados, a partir de procedimentos indicados por Wolfswinkel, Furtmueller e Wilderom (2013). Tentamos estabelecer um percurso de pesquisa endossado por critérios claros de seleção e exclusão de estudos contemplados. Esperamos que a investigação permita avançar na compreensão de dinâmicas que envolvem a presença e atuação das organizações nas mídias sociais, bem como alguns de seus impactos nebulosos, perversos e pouco conhecidos.

\section{REFERENCIAL TEÓRICO}

Compreendemos a comunicação organizacional para além das práticas oficiais e autorizadas, ou seja, extrapola a oferta de sentidos, e isso, em alguma medida, é "conduzido" pelas organizações. Em atenção à imprevisibilidade característica dos fluxos comunicacionais e ancorados em Baldissera (2008, p.169), a assumimos enquanto "processo de construção e disputa de sentidos no âmbito das relações organizacionais". Sobre isso, Baldissera (2014) destaca a potencialidade dispersiva da internalização simbólica e as incertezas diante da alteridade. Acreditamos, então, que a comunicação não se limita a um conjunto de técnicas, muito menos de ferramentas articuladas com a intencionalidade de comunicar, uma vez que os processos comunicativos são envoltos e indissociáveis da complexidade que os caracterizam.

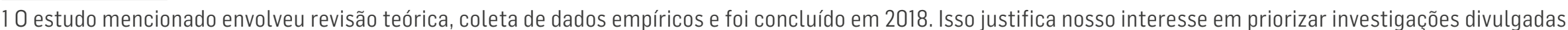

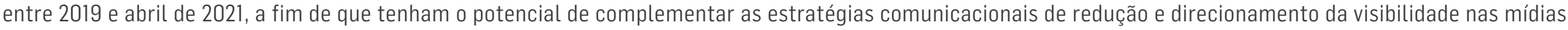
sociais já apreendidas e agregar outras práticas discursivas e sociotécnicas. 
Se por um lado as ambiências digitais agregam às organizações diversas possibilidades, é fato que também carregam consigo uma série de ameaças, devido a características como velocidade, natureza interativa e potencial de visibilidade descentralizada (Mennie, 2015). Chamamos atenção para os sentidos expressos nessas ambiências, sobretudo nas mídias sociais, que nem sempre se ajustam aos enquadramentos desejados e às práticas organizacionais autorizadas. Conforme Baldissera (2014), as tecnologias impulsionaram o aumento expressivo de sujeitos, organizações e grupos "falantes", conferindo visibilidade a sentidos antes pouco acessíveis. Assim, atravessamentos e perturbações são marcas desses espaços, o que desafia visões reducionistas de comunicação que a limitam ao campo do planejado. Os discursos organizacionais são constantemente tensionados e articulados a outros referenciais (Baldissera, 2014).

Frente a esses aspectos, as organizações desenvolvem alternativas a fim de reduzirem riscos e atingirem seus objetivos. Sobre isso, Silva (2020) destaca que há interesse em modular a visibilidade, originando estratégias de influência. Em algum nível, tais alternativas soam legítimas, porém há caminhos "secretos"2 que decorrem de lógicas indiretas de influência sobre a opinião pública. No entendimento de Silva (2020, p.34), "tais práticas são extremamente complexas, à medida que abarcam uma grande variedade de comportamentos que possuem gradações éticas diversas e que são, ainda, pouco explorados e discutidos em nossa literatura". Soma-se a isso a dificuldade em apreendê-las, pois mesmo que a organização seja protagonista, muitas vezes ela própria atua para ocultar esse envolvimento, por meio da oferta de sentidos capazes de distanciá-la e desassociá-la de tais práticas.

Ao nos referirmos a estratégias comunicacionais de redução e direcionamento da visibilidade nas mídias sociais, estamos acionando um conjunto de práticas adotadas pelas organizações com a intenção de "assumir controle" sobre os sentidos produzidos nessas ambiências. Temos clareza de que um controle irrestrito é inviável. Contudo, essa parece ser a intencionalidade, pois a tentativa é evitar ou mitigar impactos negativos e a associação expressiva a acontecimentos que as coloquem em zona de desconforto. Essas alternativas têm potência para viabilizar uma influência relevante em processos de formação de opinião, o que foi identificado em investigação empírica já mencionada (Silva; Baldissera, 2019). A partir de dados coletados originalmente para a tese de doutorado de Silva (2018), os autores asseguram que tais estratégias têm potencial danoso, pois podem retirar do campo de visibilidade questões de interesse público - ou, ainda, privilegiar ênfases que as organizações avaliem como mais oportunas. 0 quadro 1 apresenta sete estratégias e 23 ênfases mapeadas 3 .

Quadro 1: Estratégias de redução e direcionamento da visibilidade nas mídias sociais

\begin{tabular}{|c|c|c|}
\hline Estratégia & Enfase & Detalhamento \\
\hline \multirow{2}{*}{$\begin{array}{l}\text { Monitorar situações- } \\
\text { problema }\end{array}$} & Identificar riscos & $\begin{array}{l}\text { Atenção a menções sobre a organização, a pautas de seu interesse } \\
\text { e/ou a temáticas sensíveis, a partir de recursos e técnicas. }\end{array}$ \\
\hline & $\begin{array}{l}\text { Acompanhar crises } \\
\text { e desdobramentos }\end{array}$ & $\begin{array}{l}\text { Procedimentos para a sistematização de fatos e informações, } \\
\text { subsídios fundamentais para definir encaminhamentos. }\end{array}$ \\
\hline \multirow{2}{*}{$\begin{array}{l}\text { Expressar } \\
\text { posicionamento } \\
\text { institucional }\end{array}$} & $\begin{array}{l}\text { Apresentar } \\
\text { esclarecimento oficial }\end{array}$ & Evidência de argumentos e atitudes da organização acerca de pauta crítica. \\
\hline & $\begin{array}{l}\text { Responder às solicitações } \\
\text { com agilidade e } \\
\text { resolutividade }\end{array}$ & $\begin{array}{l}\text { Relação direta entre a atuação consistente das equipes de } \\
\text { atendimento e a capacidade de influenciar as percepções. }\end{array}$ \\
\hline
\end{tabular}

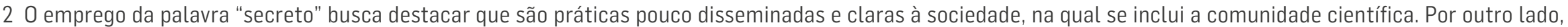

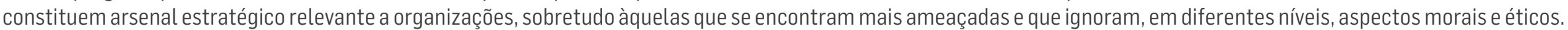

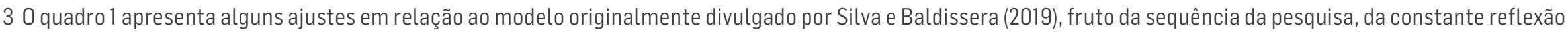
sobre essas estratégias e da tentativa de organizá-las e descrevê-las com clareza. 
Quadro 1: Estratégias de redução e direcionamento da visibilidade nas mídias sociais

\begin{tabular}{|c|c|c|}
\hline Estratégia & Ênfase & Detalhamento \\
\hline \multirow{8}{*}{$\begin{array}{l}\text { Baralhar fatos e } \\
\text { ênfases para gerar } \\
\text { incompreensão sobre } \\
\text { um acontecimento }\end{array}$} & $\begin{array}{l}\text { Desviar o enfoque para } \\
\text { pautas positivas }\end{array}$ & $\begin{array}{l}\text { Envolve a produção e disseminação de conteúdos favoráveis à } \\
\text { organização, a fim de direcionar as percepções dos públicos. }\end{array}$ \\
\hline & Gerar novos fatos & $\begin{array}{l}\text { Criação de situações, por vezes falaciosas, com capacidade de atrair } \\
\text { atenção, direcionar a visibilidade e gerar associações positivas. }\end{array}$ \\
\hline & $\begin{array}{l}\text { Promover enfoques a partir } \\
\text { de investimento financeiro }\end{array}$ & $\begin{array}{l}\text { Recorrer às possibilidades de publicidade para visibilizar } \\
\text { abordagens de interesse da organização. }\end{array}$ \\
\hline & $\begin{array}{l}\text { Infiltrar atores } \\
\text { organizacionais } \\
\text { nas discussões }\end{array}$ & $\begin{array}{l}\text { Introdução de "representantes" da organização não identificados, para } \\
\text { apresentar novos sentidos e, assim, influenciar o rumo das discussões. }\end{array}$ \\
\hline & Comprar audiência & $\begin{array}{l}\text { Contratação de interlocutores que façam circular sentidos } \\
\text { desejados pela organização, contrapondo outras perspectivas. }\end{array}$ \\
\hline & $\begin{array}{l}\text { Persuadir ou contratar } \\
\text { influenciadores digitais }\end{array}$ & $\begin{array}{l}\text { Associação a agentes relevantes nessas ambiências, a fim de que } \\
\text { ratifiquem argumentos e atitudes de interesse da organização. }\end{array}$ \\
\hline & $\begin{array}{l}\text { Desequilibrar } \\
\text { concorrente(s) }\end{array}$ & $\begin{array}{l}\text { Desvio da visibilidade não desejada para concorrente(s), } \\
\text { a partir da exposição de aspectos negativos. }\end{array}$ \\
\hline & $\begin{array}{l}\text { Otimizar a visibilidade } \\
\text { desejada nos } \\
\text { mecanismos de busca }\end{array}$ & $\begin{array}{l}\text { Emprego de técnicas para potencializar versões da organização } \\
\text { em sites relevantes na jornada de formação da opinião. }\end{array}$ \\
\hline \multirow{3}{*}{$\begin{array}{l}\text { Desconsiderar } \\
\text { associações/ } \\
\text { menções negativas }\end{array}$} & $\begin{array}{l}\text { Esquivar-se de } \\
\text { pronunciamento ou } \\
\text { não se pronunciar }\end{array}$ & $\begin{array}{l}\text { Silenciamento em relação a tópico desconfortável ou ato de sair de } \\
\text { cena integralmente com o intuito de evitar maior repercussão. }\end{array}$ \\
\hline & $\begin{array}{l}\text { Excluir ou ocultar } \\
\text { comentários e/ou postagens }\end{array}$ & $\begin{array}{l}\text { Emprego de técnicas para remover das regiões de visibilidade } \\
\text { postagens e comentários com potência de dano à organização. }\end{array}$ \\
\hline & $\begin{array}{l}\text { Conduzir a interação para } \\
\text { ambientes não visíveis }\end{array}$ & $\begin{array}{l}\text { Deslocamento de conversas para ambiências que não } \\
\text { exponham o que está sendo discutido. }\end{array}$ \\
\hline \multirow{2}{*}{$\begin{array}{l}\text { Restringir a } \\
\text { visibilidade a } \\
\text { interlocutores } \\
\text { desejados }\end{array}$} & $\begin{array}{l}\text { Captar contatos a partir } \\
\text { de técnicas anônimas }\end{array}$ & $\begin{array}{l}\text { Acesso a dados de interlocutores que se mostrem relevantes para a } \\
\text { organização implementar estratégias de visibilidade dirigida. }\end{array}$ \\
\hline & $\begin{array}{l}\text { Selecionar segmentos } \\
\text { de públicos a partir de } \\
\text { suas movimentações }\end{array}$ & $\begin{array}{l}\text { Constituição de grupos de interlocutores relevantes em função de } \\
\text { objetivos, necessidades ou desafios específicos da organização. }\end{array}$ \\
\hline \multirow{4}{*}{$\begin{array}{l}\text { Reduzir o alcance de } \\
\text { conteúdos ofertados }\end{array}$} & $\begin{array}{l}\text { Antecipar-se na apropriação } \\
\text { de mudanças de algoritmia }\end{array}$ & $\begin{array}{l}\text { Acesso a novas regras, parâmetros e lógicas de algoritmia das } \\
\text { mídias sociais a partir da proximidade com quem as controla. }\end{array}$ \\
\hline & $\begin{array}{l}\text { Explorar formatos de } \\
\text { conteúdo e horários que } \\
\text { não costumam atingir } \\
\text { visibilidade expressiva. }\end{array}$ & $\begin{array}{l}\text { Opção por formatos de conteúdo que, em função das lógicas de algoritmia, } \\
\text { tendem a não ter êxito em termos de alcance e engajamento. }\end{array}$ \\
\hline & $\begin{array}{l}\text { Não aplicar técnicas } \\
\text { de tagueamento }\end{array}$ & $\begin{array}{l}\text { Redução da visibilidade de um conteúdo pelo não uso de palavras- } \\
\text { chave - aspecto fundamental à visibilidade em algumas mídias. }\end{array}$ \\
\hline & $\begin{array}{l}\text { Restringir a visibilidade } \\
\text { a um ou poucos canais }\end{array}$ & $\begin{array}{l}\text { Diminuição do alcance do conteúdo mediante a restrição de canais, } \\
\text { o que não dialoga com interesse efetivo de visibilidade. }\end{array}$ \\
\hline \multirow[t]{2}{*}{ Estabelecer políticas } & $\begin{array}{l}\text { Implantar diretrizes para } \\
\text { empregados }\end{array}$ & $\begin{array}{l}\text { Criação de regramentos e orientações, a fim de tentar evitar associações desfavoráveis } \\
\text { à organização. }\end{array}$ \\
\hline & $\begin{array}{l}\text { Definir temas que não } \\
\text { devem ser tratados }\end{array}$ & $\begin{array}{l}\text { Mapeamento de temáticas com as quais a organização não irá se envolver ou } \\
\text { manifestar. }\end{array}$ \\
\hline
\end{tabular}

Fonte: elaborado pelo autor com base em Silva e Baldissera (2019). 
Algumas dessas alternativas, regularmente implementadas, apresentam pouca probabilidade de ferir aspectos éticos ou morais. Outras têm potencial de impedir a sociedade de conhecer temas, enquadramentos ou abordagens de interesse público, ou de prejudicar a clareza sobre determinado fato, dado o emprego intencional de recursos minuciosamente estruturados e altamente resolutivos. Além disso, podem reduzir a repercussão de algo socialmente relevante, porém que fira os interesses de uma organização. Elas permitem refletir sobre as tantas nuances que envolvem a visibilidade nas ambiências digitais, especialmente nas mídias sociais, pela relevância que hoje detêm em termos de incidência nos processos de formação de opinião e na capacidade de tornar visíveis situações por ora inoportunas, sob a ótica das organizações. Nesse sentido, ainda que predominem estudos com foco em como conquistar patamares de visibilidade, é fato que essa visibilidade nem sempre é desejada. Isso está relacionado à capacidade dos interlocutores, em outros contextos majoritariamente receptores, atuarem na (co)gestão dos acontecimentos intermidiáticos (Baldissera; Vinhola, 2020), conquistando patamares de visibilidade para suas percepções. Assim, a circulação de sentidos assume como característica as múltiplas inferências, nas quais muitas organizações buscam maneiras de influenciar e manter o poder que detinham noutros tempos.

Segundo Silva e Baldissera (2019), monitorar situações-problema compreende dinâmicas e a aplicação de recursos para identificar ameaças, mesmo que incipientes, ou acompanhar crises. A estratégia tem a intenção de produzir informações relevantes à assertividade das decisões e à compreensão de nuances e prevalências sobre o que está sendo observado. Expressar posicionamento institucional, por sua vez, está associado ao entendimento de que a organização, ao assumir protagonismo na oferta de sentidos, tem a capacidade de direcionar a visibilidade para ângulos que a interessam. Baralhar fatos e ênfases para gerar incompreensão sobre um acontecimento envolve uma série de alternativas que buscam impedir o claro discernimento sobre algo. Sob essa perspectiva, a coexistência de sentidos contraditórios ou dissonantes tende a reduzir associações negativas à organização.

Desconsiderar associações/menções negativas é uma estratégia fundamentada na visão de que o silenciamento ou o ato de se retirar de uma discussão pública, por vezes, é capaz de evitar uma exposição demasiada e desconfortável. Restringir a visibilidade a interlocutores desejados envolve a aplicação de técnicas de segmentação para que a organização se dirija especificamente a grupos e sujeitos que manifestem determinados comportamentos, indicando pré-disposição às narrativas e aos argumentos visibilizados. Reduzir o alcance de conteúdos ofertados trata das boas práticas que favorecem à visibilidade, porém aplicadas em sentido contrário. Ou seja, diante do domínio de caminhos para ascender a níveis expressivos de visibilidade, como formatos e horários mais resolutivos, a organização opta por praticar exatamente o oposto. Nesse caso, é provável que busque provocar uma "sensação de visibilidade", quando em realidade o desejo é que ela seja parcial e restrita. Por fim, estabelecer políticas consiste em determinações basilares que possam evitar ou reduzir a visibilidade de situações contrárias aos anseios da organização.

Vale comentar que essas estratégias costumam ser conformadas por múltiplos arranjos e composições. "Elas são orquestradas de modo combinado, em cadeia/sequência ou concomitantemente, a partir dos desafios, habilidades, níveis de responsabilidade e compromissos éticos, ou da ausência deles, dos profissionais que as propõem e conduzem" (Silva, 2018, p.238). Além disso, elas não se limitam a uma ou a outra mídia social, ainda que Silva e Baldissera (2019) reconheçam que características específicas de cada plataforma possam facilitar ou dificultar a conquista dos efeitos desejados. Nesse aspecto, é oportuno clarificar a natureza das estratégias que investigamos. Algumas são construções fundamentalmente discursivas, suportadas ou potencializadas por aspectos sociotécnicos, ou seja, pela dinâmica social e constituição tecnológica das mídias (Lasta, 2017). Outras se valem unicamente de apurado conhecimento, o que permite às organizações prognosticarem cenários e tomarem decisões que lhes pareçam oportunas - como ocorre nas estratégias de monitoramento de situações-problema e de estabelecimento de políticas.

Os aspectos que discutimos se integram à pauta de prevenção de riscos e gestão de crises de imagem e reputacionais. As mídias sociais, enquanto espaços também de vulnerabilidade, se tornam palcos crescentes de escândalos, de tensionamentos de alta magnitude e de visibilidade de sentimentos negativos (Einwiller; Steilen, 2015). Vašičková (2019), em revisão de literatura 
sobre gestão de crises, destaca a visão processual desses fenômenos, o que inclui a energia despendida pelas organizações na previsão e preparação a crises potenciais. Logo, há estímulos para que se configure enquanto processo proativo capaz de identificar precocemente sinais de alerta. Isso estimula o investimento expressivo no monitoramento das dinâmicas e expressões que envolvam determinada organização ou que a ela possam impactar, noção que é reiterada pela primeira estratégia apresentada no quadro 1.

\section{PROCEDIMENTOS METODOLÓGICOS}

Até aqui, recorremos à técnica de pesquisa bibliográfica (Gil, 2021). Para a sequência do estudo, que envolve uma discussão teórica capaz de responder ao segundo objetivo, optamos por recorrer à Teoria Fundamentada em Dados, especificamente a etapas sugeridas por Wolfswinkel, Furtmueller e Wilderom (2013). Os autores indicam protocolos de investigação a fim de que ela seja desenvolvida com base em dados e em decisões tecnicamente consistentes. Inicialmente, definimos critérios de pesquisa de inclusão e exclusão, ou seja, termos que se adequam ao nosso desejo de compreender as estratégias discursivas e sociotécnicas de redução e direcionamento da visibilidade nas mídias sociais. Da mesma forma, suprimimos aqueles que não se mostram relevantes, pois inclinariam a pesquisa a outros aspectos.

A escolha dos recursos de pesquisa é uma etapa determinante no processo de revisão teórica. Em nosso estudo, optamos pela base de dados Scopus, da empresa Elsevier (2021), em razão de sua amplitude e alcance global e das alternativas de refinamento das pesquisas, capazes de favorecer a assertividade dos resultados. Com esta definição, aplicamos os termos previamente definidos, com a intenção de concluir quais são as nomenclaturas mais aderentes, o que nos levou à combinação de termos apresentados na figura 1. A priorização da língua inglesa atende a uma orientação da própria base de dados, visando a resultados mais expressivos.

Figura 1: Termos específicos de pesquisa

\begin{tabular}{|c|c|c|c|}
\hline $\begin{array}{l}\text { reduction } \\
\text { redução }\end{array}$ & $\begin{array}{c}\text { silencing } \\
\text { silenciamento }\end{array}$ & $\begin{array}{l}\text { influence } \\
\text { influência }\end{array}$ & $\begin{array}{c}\text { targeting } \\
\text { direcionamento }\end{array}$ \\
\hline \multirow[t]{2}{*}{$\begin{array}{l}\text { visibility } \\
\text { visibilidade }\end{array}$} & $\begin{array}{l}\text { invisi bility } \\
\text { invisibilidade }\end{array}$ & $\begin{array}{l}\text { opinion } \\
\text { opinião }\end{array}$ & $\begin{array}{l}\text { undertstanding } \\
\text { compreensão }\end{array}$ \\
\hline & $\begin{array}{l}\text { Social media } \\
\text { midia ou rede social }\end{array}$ & $\begin{array}{l}\text { Social medias } \\
\text { midias ou redes s ociais }\end{array}$ & \\
\hline $\begin{array}{c}\text { organization } \\
\text { organização }\end{array}$ & $\begin{array}{c}\text { organizations } \\
\text { org anizações }\end{array}$ & $\begin{array}{l}\text { company } \\
\text { empresa }\end{array}$ & $\begin{array}{l}\text { companies } \\
\text { empresass }\end{array}$ \\
\hline
\end{tabular}

Fonte: elaborada pelo autor.

A decisão de trabalhar com termos próximos ou correlatos evita a desconsideração de estudos que possam ser afins ao objeto de estudo. Os buscadores avaliam a presença dessa combinação em títulos, resumos e palavras-chave, o que nos levou, inicialmente, a 694 artigos publicados em periódicos. Sobre esse quantitativo, aplicamos os seguintes filtros: 1) que os estudos tenham as Ciências Sociais ou Negócios, Gestão e Contabilidade como áreas de estudo ; e 2) que os artigos tenham sido publicados entre 2019 e abril de 2021, no intuito de privilegiar investigações que dialoguem com as características contemporâneas das mídias sociais e que sucedam o período de desenvolvimento do estudo de Silva e Baldissera (2019). Então,

4 Essas são opções de filtro pré-definidas pela plataforma. 
chegamos a 215 artigos, dos quais 111 são da área de Ciências Sociais e 104 de Negócios, Gestão e Contabilidade. Antes de avançar, é oportuno destacar que esse primeiro achado já permite afirmar que nosso objeto de estudo não se insere apenas em pesquisas estritamente comunicacionais, mas que tem relevo sob a perspectiva administrativa - potencialmente pelos riscos que representam às organizações.

Na sequência, avançamos para a etapa de refinamento da amostra, que consiste na leitura dos títulos, resumos e palavraschave dos subsídios pré-selecionados. 0 intuito é diagnosticar aqueles que efetivamente apresentam relações diretas com os objetivos e com o foco de investigação. Atentamos para aspectos como: interface explícita com o nosso objeto de pesquisa e relação com práticas organizacionais ou com processos em mídias sociais que envolvam organizações. Tal observação culminou na relação de artigos expressa no Quadro 2.

Quadro 2: Artigos selecionados para a discussão teórica

\begin{tabular}{|c|c|c|c|c|}
\hline Ano & Autor(es) & Título & Periódico & Razões para a seleção \\
\hline 2019 & Liu & $\begin{array}{l}\text { "A big data approach to examining social } \\
\text { bots on Twitter" (Uma abordagem de big data } \\
\text { para examinar bots sociais no Twitter) }\end{array}$ & $\begin{array}{l}\text { Journal of } \\
\text { Services } \\
\text { Marketing }\end{array}$ & $\begin{array}{l}\text { Revela a incidência de } \\
\text { automação maliciosa em } \\
\text { uma mídia social, bem } \\
\text { como seus impactos. } \\
\end{array}$ \\
\hline 2019 & $\begin{array}{l}\text { Tuten e } \\
\text { Perotti }\end{array}$ & $\begin{array}{l}\text { "Lies, brands e social media" (Mentiras, } \\
\text { marcas e mídias sociais) }\end{array}$ & $\begin{array}{l}\text { Qualitative } \\
\text { Market Research }\end{array}$ & $\begin{array}{l}\text { Indica a influência da } \\
\text { imprensa sobre os } \\
\text { rumos de discussões nas } \\
\text { mídias sociais, além de } \\
\text { periculosidades inerentes. }\end{array}$ \\
\hline 2019 & $\begin{array}{c}\text { Cooper; } \\
\text { Stavros } \\
\text { e Dobele }\end{array}$ & $\begin{array}{l}\text { "Domains of influence: exploring negative sentiment } \\
\text { in social media" (Domínios de influência: explorando } \\
\text { o sentimento negativo nas mídias sociais) }\end{array}$ & $\begin{array}{l}\text { Journal of } \\
\text { Product } \\
\text { and Brand } \\
\text { Management }\end{array}$ & $\begin{array}{l}\text { Destaca de que modo as } \\
\text { organizações previnem e } \\
\text { reagem diante da visibilidade } \\
\text { de sentimentos negativos } \\
\text { nas mídias sociais. }\end{array}$ \\
\hline 2019 & $\begin{array}{l}\text { Ross } \\
\text { et al. }\end{array}$ & $\begin{array}{l}\text { "Are social bots a real threat? An agent-based } \\
\text { model of the spiral of silence to analyse the impact } \\
\text { of manipulative actors in social networks" (Os bots } \\
\text { sociais são uma ameaça real? Um modelo da espiral } \\
\text { do silêncio baseado em agentes para analisar o } \\
\text { impacto de atores manipuladores nas mídias sociais) }\end{array}$ & $\begin{array}{l}\text { European } \\
\text { Journal of } \\
\text { Information } \\
\text { Systems }\end{array}$ & $\begin{array}{l}\text { A partir de um experimento } \\
\text { virtual, simula intervenções } \\
\text { de bots sociais e associa } \\
\text { os resultados à teoria } \\
\text { da espiral do silêncio e à } \\
\text { prática de astroturfing. }\end{array}$ \\
\hline 2020 & Altamini & $\begin{array}{l}\text { "Who controls the Arab public sphere in the } \\
\text { era of new media, the new revolutionists or } \\
\text { the deep state?" (Quem controla a esfera } \\
\text { pública árabe na era das novas mídias, os novos } \\
\text { revolucionários ou o Estado profundo } ? \text { ?) }\end{array}$ & $\begin{array}{l}\text { Journal of } \\
\text { Content, } \\
\text { Community and } \\
\text { Communication }\end{array}$ & $\begin{array}{l}\text { Associa o potencial libertador } \\
\text { da internet a novas dinâmicas } \\
\text { sociais em países árabes e } \\
\text { apresenta medidas adotadas } \\
\text { por governos para dificultar } \\
\text { ou impedir a visibilidade } \\
\text { de sentidos dissidentes. }\end{array}$ \\
\hline
\end{tabular}

Fonte: elaborado pelo autor (2021).

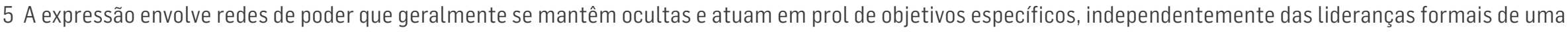
nação. 
No próximo tópico dedicamo-nos a comentar as contribuições que nos parecem mais relevantes, extraídas dos cinco artigos selecionados. A correlação mais explícita com elementos da discussão teórica anteriormente apresentada ocorre nas considerações finais, quando nos dirigimos às contribuições dessas pesquisas ao mapeamento anteriormente realizado por Silva e Baldissera (2019).

\section{RESULTADOS}

Liu (2019) investiga bots sociais, recursos viabilizados pelo avanço da inteligência artificial e pelo aprendizado de máquina. Eles produzem conteúdos e promovem interações nas mídias sociais, simulando comportamento humano. Com isso, influenciam percepções sobre algo a partir de intencionalidades precisas, porém escusas. 0 estudo trata especificamente da prevalência e dos impactos dessa prática no Twitter e recupera pesquisas que evidenciam a resolutividade de bots sociais a serviço de objetivos institucionais e mercadológicos de organizações e de interesses no âmbito político-eleitoral. A partir da coleta de dados, que envolveu 24 organizações e aproximadamente 29 milhões de postagens, foi possível categorizar os conteúdos conforme a procedência: das próprias organizações, em perfis oficiais; de perfis autênticos, vinculados a uma pessoa e de bots sociais.

A classificação foi realizada através de uma ferramenta de modelagem probabilística. É possível identificar os conteúdos decorrentes de perfis falsos em função de algumas variáveis, tais como 0 alto volume e frequência de postagens em curto espaço de tempo, além de traços e padrões de estilo linguístico. Das mensagens aparentemente produzidas por perfis autênticos, 31,2\% provêm, em realidade, de perfis automatizados. Ou seja, não estamos tratando de um recurso inexpressivo, visto que representa um terço das postagens. Liu (2019) enfatiza que os bots sociais incidem na produção de desinformação, fabricam críticas e espalham notícias falsas. Assim, abafam opiniões genuinamente humanas, ganhando força à medida que os conteúdos carregam carga emotiva, dispositivo eficaz para a distorção e manipulação de sentimentos (Liu, 2019). Ainda, há um destaque sobre a incipiência de estudos que tratem desse fenômeno emergente nas mídias sociais, o que poderia conferir visibilidade a tais práticas perversas, assim como ao grau de envolvimento de organizações.

Tuten e Perotti (2019) apresentam outro aspecto, o da influência da cobertura midiática sobre os rumos das discussões nas mídias sociais. 0 estudo permite compreender que os conteúdos produzidos por veículos de imprensa e agências de notícias são altamente reverberados nessas ambiências, pois acabam incidindo na opinião dos públicos acerca do que está sendo pautado. Logo, é de interesse das organizações abrandar ou evitar enquadramentos indesejados, inclusive pelo elevado grau de confiabilidade costumeiramente associado a tais veículos e agências. Porém, os autores assinalam que as condições de produção jornalística podem conferir visibilidade a boatos, pois nem sempre há verificação adequada e suficiente. Por vezes, a própria repercussão de um tema nas mídias sociais é noticiada, assumindo o lugar de "acontecimento" no lugar do fato em si. Nos bastidores, é possível relacionar tais práticas a interesses mercadológicos da imprensa e à busca por audiência.

Empiricamente, a investigação proposta por Tuten e Perotti (2019) envolve uma organização que teve seu nome associado a um acontecimento não comprovado. Foram produzidas e divulgadas diversas notícias sobre o boato, antes da organização ter a capacidade de esclarecer que se tratava de uma falácia. Para chegar aos resultados, os pesquisadores coletaram os conteúdos jornalísticos e quaisquer comentários nas mídias sociais alusivos à organização, ao longo de 30 meses. A análise dos dados evidencia que as notícias sobre a falsa alegação tiveram um enquadramento predominantemente negativo e que, mesmo com novas abordagens sequentes à retratação, 88\% dos conteúdos compartilhados nas mídias sociais ofertam sentidos negativos sobre a organização. Ou seja, há uma forte relação entre abordagens prematuras de veículos e agências e os conteúdos que são "privilegiados" nas mídias sociais. 
Em síntese, a pesquisa esclarece a indissociabilidade entre a imprensa e a circulação de sentidos nessas ambiências e que organizações que desejam estar menos vulneráveis precisam ser competentes e ágeis no relacionamento com jornalistas, evitando notícias que exponham situações e enquadramentos inverídicos. Quando isso não for possível, além da tentativa de correção junto a veículos e agências, as organizações precisam atuar em estratégias próprias de disseminação das suas versões nas mídias sociais, dado que os conteúdos noticiosos que oferecem uma versão favorável tendem a não ter a mesma visibilidade conquistada pelos negativos. Os aprendizados também fazem crer que a articulação de organizações com os veículos de imprensa, muitas vezes mediante dinâmicas, lógicas e acordos pouco claros à sociedade, pode ser altamente resolutiva para direcionar a visibilidade nas mídias sociais.

Cooper, Stavros e Dobele (2019) avaliam como as organizações atuam preventivamente e também de modo reativo à expressão de sentimentos negativos nas mídias sociais. Essa pesquisa dá relevo ao esforço das organizações para evitar crises de imagem e impactos à reputação ou a fim de mitigar danos - em situações nas quais as investidas organizacionais não forem suficientes para impedi-los. Na discussão teórica proposta pelos autores, merece destaque a ressalva de que, às organizações, pode interessar a circulação de sentidos contraditórios nas ambiências que investigamos, pois estudos comprovam que essa dinâmica aumenta a participação e o envolvimento dos interlocutores e a visibilidade da organização, o que pode interessar em determinadas conjunturas. Esse argumento permite compreender que a constituição de eventos críticos nem sempre é algo indesejado, uma vez que pode ser uma estratégia para acessar zonas de visibilidade.

0 estudo é realizado por meio de entrevistas com profissionais que atuam na gestão de mídias sociais e de comentários coletados durante três meses na mídia Facebook. No total, são seis organizações envolvidas, o que permite uma análise comparativa e a compreensão sobre como são as atitudes das organizações em situações com potencial danoso, ou efetivamente negativas. Os resultados indicam que a agilidade, a resolutividade e a humildade em reconhecer equívocos são fundamentais no tratamento de comentários negativos e nas narrativas assumidas nessas situações. Eles também descobriram que a decisão por terceirizar o atendimento dessas demandas, ainda que responda ao desejo de eficiência, tende a enfraquecer o relacionamento e a proximidade entre organização e públicos de interesse. Especificamente em relação à produção de conteúdos nessas ambiências, Cooper, Stavros e Dobele (2019) compreendem que coabitam duas camadas, uma orgânica e outra dominante, que favorecem a reverberação de conteúdos por meio de investimento pago. A primeira possibilidade apresenta resultados inferiores em termos de alcance, sinalizando a capacidade de investimento financeiro em "definir" que algo deve ser visto e quais vieses terão maior probabilidade de se destacarem. Por fim, asseguram que processos e sistemas de alerta precoce são altamente resolutivos na prevenção de crises.

Ross et al. (2019) iniciam a discussão reconhecendo que a circulação de sentidos nas mídias sociais está emaranhada por interesses diversos, de organizações e indivíduos. Asseguram que as informações visíveis nessas ambiências influenciam fortemente a opinião pública, o que vem despertando, de modo crescente, o desejo de manipular conteúdos, disseminar notícias falsas e desenvolver bots sociais. Com o passar dos anos, o nível de profissionalização desses recursos tem tornado cada vez mais dificultosa a avaliação do que é ou não autêntico - sobretudo àqueles que desconhecem técnicas e recursos empregados. 0 estudo proposto está encorado na "espiral do silêncio", perspectiva teórica que pontua a redução das dissidências sobre algo, na medida em que um sujeito reconhece que seus argumentos são minoria dentre os sentidos em circulação. Isso tende a resultar em falta de autoconfiança e omissão da opinião.

No contexto das mídias sociais, os pesquisadores destacam que essa teoria tem recebido atenção, especialmente pela capacidade dos bots sociais visibilizarem de modo exacerbado determinados argumentos, produzindo sentidos de expressividade - 0 que se configura como falacioso e manipulatório. Com isso, pessoas que se identificam com a visão tendem a expressá-la publicamente; as que discordam tendem a se calar, pois receiam se isolar socialmente. Os autores também articulam essa 
lente à prática de astroturfing, entendida como a produção de atos ou símbolos capazes de evidenciar expressivo apoio a algo, como se fosse uma dinâmica genuína, enquanto de fato é estruturada a partir de intencionalidades específicas.

Em nível empírico, a proposta envolve um experimento virtual modelado para simular interações em rede e os impactos desencadeados pela manifestação de bots sociais, em diferentes níveis de incidência. A experiência revelou a prevalência da opinião manifestada mediante esses recursos, mesmo em testagens em que o quantitativo de bots era proporcionalmente pequeno em comparação a perfis autênticos. Os sentidos que eles acionam tendem a ser acolhidos e percebidos como opinião majoritária, o que induz a espirais de silenciamento e à queda da reverberação de pontos de vista dissidentes. As influências sociais são ainda mais expressivas quando esses recursos se dirigem e obtêm eficácia junto a interlocutores (reconhecidos como) legítimos. À medida que reverberam tais informações, atribuem a elas graus de autenticidade e confiabilidade. Na prática, então, os bots sociais influenciam a opinião pública. Ross et al. (2019) reiteram que eles podem minar consideravelmente os processos democráticos e discussões de relevo sob a perspectiva do interesse público. Nesse sentido, são urgentes orientações sobre a natureza dessas práticas, pois há muitos interesses conflitantes coabitando nessas ambiências e conduzindo a manipulações e jogos de poder pouco evidentes. Na visão dos autores, as "descobertas devem alertar ainda mais o campo da política e governança na internet, bem como os gerentes de plataformas de mídias sociais para desenvolver maneiras precisas de detectar e excluir rapidamente os bots sociais" (Ross et al., 2019, p.408, tradução nossa $\left.{ }^{6}\right)$. Avaliamos, infelizmente, que este parece um horizonte distante.

Altamini (2020), em perspectiva mais ampla, tem como foco de investigação os tensionamentos e disputas por visibilidade em ambiências digitais nos países árabes. Ao reconhecer o impacto dos avanços tecnológicos na mobilização social na história recente, opta por direcionar sua reflexão a medidas adotadas por regimes políticos com o intuito de exercer domínio, modular e limitar a visibilidade. Para isso, propõe uma revisão de literatura sobre o tema e a observação de acontecimentos recentes. Uma estratégia destacada envolve o desligamento ou interrupção parcial do acesso à internet, conduzida pelo Estado, o que costuma ocorrer de três modos: bloqueio do acesso à internet e a todas as suas plataformas; bloqueio a sites ou aplicativos específicos; e imposição, a operadoras de telecomunicações ou provedores de serviços de internet, da diminuição da qualidade e velocidade da internet. Esses caminhos são vistos pelos governos desses países como resolutivos para coibir a força de manifestações incômodas, as articulações em rede e a circulação de sentidos dissidentes. Especificamente em relação às mídias sociais, Altamini (2020) destaca que o impedimento de acesso a elas é a estratégia mais usual, o que conduz opiniões a zonas de obscuridade, uma vez que são retiradas arbitrariamente de cena. Com isso, fica claro que a censura está associada a estratégias de redução da visibilidade, capazes de produzir até mesmo invisibilidade midiática.

Em nível também extremo está a constituição de leis que coíbem expressões e limitam movimentações de sujeitos em ambiências digitais. Observemos o exemplo apresentado por Altamini (2020) sobre essas iniciativas: em agosto de 2018, o presidente do Egito assinou a Lei de Combate aos Crimes Cibernéticos, estrutura legal que assegura o bloqueio de sites avaliados como "ameaças à segurança nacional". Indivíduos que, de algum modo, consigam acessá-los, podem ser presos por até um ano; a pena aos criadores ou gerenciadores é de até dois anos. Ainda nesse país, o Parlamento promulgou três projetos de lei, também em 2018, com uma série de restrições a mídias on-line: nenhum site pode ser criado sem a anuência do Conselho de Regulação da Mídia; e uma conta pessoal em mídias sociais com mais de 5 mil seguidores é compreendida como "veículo de comunicação", e isso permite que um sujeito seja multado ou tenha seu perfil bloqueado se for avaliado como risco ao Estado. Somado a isso - e não se referindo especificamente ao Egito - o autor alerta que governos vêm empregando bots sociais para influenciar a formação de opinião. Dentre as evidências coletadas, Altamini (2020) expõe práticas capazes

6 No original: "Our findings should further alert the field of internet policy and governance as well as the managers of social media platforms to develop accurate ways to detect and quickly delete social bots" (Ross et al., 2019, p.408). 
de inundar as ambiências digitais com conteúdos triviais, pouco relevantes do ponto de vista político e social. Há, aqui, um caminho para baralhamento ou desvio da visibilidade.

\section{CONSIDERAÇÕES FINAIS}

A jornada metodológica que propomos nos permitiu aprofundar aspectos mapeados por Silva e Baldissera (2019), ao mesmo tempo em que explicitou preocupação relevante da comunidade científica sobre o refinamento de técnicas de automação. Nesse caminho, gera apreensão a alta incidência dos bots sociais e a comprovação de que tais recursos são altamente influentes nos processos de formação de opinião (Altamini, 2020; Liu, 2019; Ross et al., 2019). Chama atenção, também, a incipiência de estudos que tragam para o centro da reflexão o grau de envolvimento de organizações nessas práticas, aspecto que está imbricado aos desafios metodológicos de evidenciar dinâmicas que têm como condição de existência manter-se ocultas, total ou parcialmente. Em alguns momentos, as organizações são posicionadas apenas como vítimas dessas dinâmicas, quando não é preciso muito para concluir que as investidas dialogam com seus interesses. Não temos condições de afirmar a expressividade desse envolvimento em nível mundial, mas a realidade brasileira apontada por Silva e Baldissera (2019) esclarece quão presentes são essas práticas no assessoramento de agências de comunicação digital a organizações. Reiteramos que não se trata de algo brando, pouco explorado. 0 que permanece às margens é justamente a problematização expressiva sobre impactos à sociedade e o quanto nossa visão está associada a tais movimentos e tentativas de modulação da visibilidade.

Ao retomarmos as estratégias de redução e direcionamento da visibilidade nas mídias sociais identificadas por Silva e Baldissera (2019), ponto de partida desta pesquisa, parece-nos oportuno agregar três ênfases a estratégias já expressas (Quadro 3). Evidentemente, não queremos simplificar as contribuições, pois, como vimos, há inúmeras nuances e também perversidades que envolvem tais práticas. A tentativa é exercitar uma visão congruente sobre essas estratégias, dando a ver os tantos caminhos possíveis já identificados.

Quadro 3: Ênfases acrescentadas ao mapeamento de Silva e Baldissera (2019)

\begin{tabular}{|l|l|l|}
\multicolumn{1}{|c|}{ Estratégia } & \multicolumn{1}{c|}{\begin{tabular}{c}
\multicolumn{1}{c|}{ Énfase } \\
Baralhar fatos e ênfases \\
para gerar incompreensão \\
sobre um acontecimento
\end{tabular}} & $\begin{array}{l}\text { Aciona recursos automatizados de desinformação } \\
\text { e disseminação de notícias falsas em larga escala, } \\
\text { altamente influentes sobre a opinião pública. }\end{array}$ \\
\hline $\begin{array}{l}\text { Desconsiderar associações/ } \\
\text { menções negativas }\end{array}$ & $\begin{array}{l}\text { Bloquear ou dificultar } \\
\text { acesso à internet ou a sites } \\
\text { e aplicativos específicos }\end{array}$ & $\begin{array}{l}\text { Censura conteúdos por meio da } \\
\text { interrupção dos serviços de internet ou do } \\
\text { acesso a plataformas, desmobilizando a } \\
\text { expressividade de opiniões embativas. }\end{array}$ \\
\hline $\begin{array}{l}\text { Expressar posicionamento } \\
\text { institucional }\end{array}$ & $\begin{array}{l}\text { Exvolve a priorização de agências e veículos } \\
\text { produtores de notícia ao posicionar a } \\
\text { junto à imprensa }\end{array}$ \\
\hline $\begin{array}{l}\text { versão da organização sobre algo. Parte da } \\
\text { compreensão de que os conteúdos por eles } \\
\text { visibilizados carregam sentidos de legitimidade } \\
\text { ao reverberarem nas mídias sociais. }\end{array}$
\end{tabular}

Fonte: elaborado pelo autor.

Reiteramos que essas práticas não costumam ser aplicadas isoladamente. Por exemplo: é possível associar a infiltração de bots sociais à geração de novos fatos ou, ainda, ao desvio de enfoque para pautas positivas. Já ardilosas, as estratégias 
ganham novos contornos por essa potencialidade de articulação conforme os interesses e as forças em jogo, em cada conjuntura. Esperamos que novas pesquisas se dediquem a essas questões. Inclusive, parece-nos que os artigos selecionados inspiram a aproximar campos como a comunicação organizacional, ciência de dados, marketing, psicologia e sistemas de informação, dentre outros, para obter dados esclarecedores. Está claro que a democracia e horizontalidade, atributos muitas vezes associados ingenuamente às mídias sociais, são desmantelados quando nos deparamos com essas práticas. Opiniões são conduzidas a zonas de invisibilidade ou de pouca visibilidade a partir de arsenal cada vez mais robusto, minucioso e amparado pelo "desenvolvimento" tecnológico. Os impactos - ao menos os que já conseguimos evidenciar - indicam a força dessas estratégias, o que precisa ser problematizado em nível científico, social e político. Ignorá-las representa admitir as consequências que provavelmente conheceremos tardiamente.

\section{REFERÊNCIAS}

ALTAMINI, Nawaf Abdelhay. Who controls the arab public sphere in the era of new media, the new revolutionists or the deep state? Journal of Content, Community \& Communication, Madhya Pradesh, v.12, ano6, p.312-323, 2020.

BALDISSERA, Rudimar. Comunicação e significação e significação na construção da imagem-conceito. Fronteiras, São Leopoldo, v.10, n.3, p.193-200, 2008. DOl: https://doi.org/10.4013/5397.

BALDISSERA, Rudimar. Comunicação organizacional e gestão de marca: redes de organizações por articulação conceitual. In: ENCONTRO ANUAL DA ASSOCIAÇÃO NACIONAL DOS PROGRAMAS DE PÓS-GRADUAÇÃO EM COMUNICAÇÃO, 23., 2014, Belém. Anais [...]. Belém: Compós, 2014. Disponível em: http://compos.org.br/encontro2014/anais. Acesso em: 28 abr. 2021.

BALDISSERA, Rudimar; VINHOLA, Bruno. Midiatização e comunicação organizacional: aproximações tentativas. Animus, Santa Maria, v.19, n.39, p.22-39, 2020. DOI: https://doi.org/10.5902/2175497739595.

BULGACOV, Sergio; MARCHIORI, Marlene. Estratégia como prática: a construção de uma realidade social em processos de interação organizacional. In: MARCHIORI, Marlene (org.). Comunicação e organização: reflexões, processos e práticas. São Caetano do Sul: Difusão, 2010. p.149-166.

COOPER, Tony; STAVROS, Constantino; DOBELE, Angela R. Domains of influence: exploring negative sentiment in social media. Journal of Product and Brand Management, v.28, n.5, p.684-699, 2019.

EINWILLER, Sabine; STEILEN, Sarah. Handling complaints on social network sites - an analysis of complaints and complaint responses on Facebook and Twitter pages of large US companies. Public Relations Review, v.41, n. 2, p.195-204, 2015. DOI: https://doi.org/10.1016/j.pubrev.2014.11.012.

GIL, Antonio Carlos. Métodos e técnicas de pesquisa social. 7.ed. São Paulo: Atlas, 2021.

LASTA, Elisangela. Estratégias sociotécnicas de visibilidade e legitimidade na comunicação organizacional em rede. In: CONGRESSO BRASILEIRO DE CIÊNCIAS DA COMUNICAÇÃO, 40., 2017, Curitiba. Anais [...]. Curitiba: Universidade Positivo, 2017. Disponível em https://professor.ufrgs.br/elisangela-lasta/files/r12-2846-1.pdf. Acesso em: 28 abr. 2021.

LITTLEJOHN, Stephen W. Fundamentos teóricos da comunicação humana. Rio de Janeiro: Zahar, 1982. 
LIU, Xia. A big data approach to examining social bots on Twitter. Journal of Services Marketing, v.33, n.4, p.369-379, 2019. DOI: https://doi.org/10.1108/JSM-02-2018-0049.

MENNIE, Phill. Social media risk and governance: managing enterprise risk. Philadelphia: Kogan Page, 2015.

ROSS, Björn et al. Are social bots a real threat? An agent-based model of the spiral of silence to analyse the impact of manipulative actors in social networks. European Journal of Information Systems, v.28, n. 4, p.394-412, 2019. D0I: https:// doi.org/10.1080/0960085X.2018.1560920.

SILVA, Daniel Reis. Organizações privadas e lógicas indiretas de influência sobre a opinião pública: problemática e desafios para pesquisa. In: FARIAS, Luiz Alberto; LEMOS, Else; REBECHI, Cláudia Nociolini (org.). Opinião pública, comunicação e organizações: convergências e perspectivas contemporâneas. São Paulo: Abrapcorp, 2020. p.32-50.

SILVA, Diego Wander da. Comunicação organizacional e as estratégias de invisibilidade e de redução/direcionamento da visibilidade nas mídias sociais. 2018. Tese (Doutorado em Comunicação e Informação) - Universidade Federal do Rio Grande do Sul, Porto Alegre, 2018.

SILVA, Diego Wander da; BALDISSERA, Rudimar. Comunicação organizacional e as estratégias de invisibilidade e de redução/ direcionamento da visibilidade nas mídias sociais. Organicom, São Paulo, v.16, n.31, p.16-26, 2019. DOl: https://doi.org/10.11606/ issn.2238-2593.organicom.2019.163239.

TUTEN, Tracy; PEROTTI, Victor. Lies, brands and social media. Qualitative Marketing Research, v.22, n.1, p.5-13, 2019. DOI: https://doi-org.ez94.periodicos.capes.gov.br/10.1108/QMR-02-2017-0063.

VAŠÍCKKOVÁ, Veronica. Crisis management process: a literature review and a conceptual integration. Acta Oeconomica Pragensia, Praga, v.27, p.61-77, 2019. DOI: https://doi.org/10.18267/j.aop.628.

WOLFSWINKEL, Joost F.; FURTMUELLER, Elfi; WILDEROM, Celeste P. M. Using grounded theory as a method for rigorously reviewing literature. European Journal of Information Systems, Londres, v.22, p.45-55, 2013. DOI: https://doi.org/10.1057/ ejis.2011.51.

Artigo recebido em 29.04.2021 e aprovado em 09.08.2021. 